\title{
Controlled Oxidation of Dextran for Evolution of Polyether Segment Bearing Pendant Carboxyl Groups for Corrosion Inhibition Applications
}

\author{
Kenichi OYAIZU, ${ }^{1}$ Aritomo YAMAGUCHI, ${ }^{2}$ Takamitsu HAYASHI, ${ }^{2}$ \\ Yukiaki NakAmura, ${ }^{2}$ Daisuke YoshiI, ${ }^{2}$ Yuji ITo, ${ }^{2}$ and Makoto YUASA ${ }^{1,2,}$, \\ ${ }^{1}$ Institute of Colloid and Interface Science, Tokyo University of Science, \\ 1-3 Kagurazaka, Shinjyuku-ku 162-8601, Japan \\ ${ }^{2}$ Department of Pure and Applied Chemistry, Faculty of Science and Technology, \\ Tokyo University of Science, 2641 Yamazaki, Noda 278-8510, Japan
}

(Received August 22, 2005; Accepted November 17, 2005; Published April 15, 2006)

\begin{abstract}
Partially oxidized dextran containing carboxyl groups was prepared as an environmentally benign organic corrosion inhibitor for mild steel. Introduction of carboxyl groups was accomplished by oxidation of dextran using sodium hypochlorite under basic conditions. The structure of the product was confirmed by spectroscopic measurements. GPC analysis revealed that oxidation of dextran proceeded without significant molecular-weight degradation. ${ }^{1} \mathrm{H}$ NMR spectra revealed that up to 1.3 carboxyl groups per repeating unit were introduced into the polymer. The product showed moderate corrosion inhibition activity for mild steel, and biodegradability under conditions for cooling water systems. [DOI 10.1295/polymj.38.343]

KEY WORDS Dextran / Oxidation / Polycarboxylate / Hypochlorite / Corrosion Inhibitor / Spectroscopy /
\end{abstract}

New perspectives open up with developments to utilize corrosion inhibition by water-soluble polycarboxylates such as poly(acrylate) and related polymers. ${ }^{1}$ These compounds inhibit corrosion of mild steel and stainless steel by adsorbing at the metal surface through carboxyl groups, which also lead to effective scale inhibition for calcium carbonate in cooling water systems. ${ }^{2-6}$ Despite these practical benefits, however, the utilization of these compounds is still controversial, especially with regard to degradability and environmental safety. One strategy to reduce the potential environmental impact aims at the use of nature-identical agents belonging to various groups of organic acids. Here we report that partially oxidized polysaccharides are environmentally benign corrosion inhibitors for steels.

Oxidation of primary alcohol groups in polysaccharides to uronic acids has widely been investigated using various oxidants such as $\mathrm{NO}_{2}{ }^{7-9}$ and $\mathrm{Pt} / \mathrm{O}_{2},{ }^{10,11}$ but the reaction is accompanied by substantial degradation of the polymer and by non-selective oxidation. A significant increase in the selectivity was accomplished by Besemer et al. using 2,2,6,6-tetramethyl-1-piperidinyloxy as a mediator and hypochlorite/bromide as an ultimate oxidant under basic conditions $(\mathrm{pH} 10-11){ }^{12}$ This reaction was exploited for determination of a small amount of primary alcohol groups as a defect in dextran, a (1 $\rightarrow 6)$ - $\alpha$-D-glucan. ${ }^{12}$ At present, chemical modification of dextran is widely investigated for bio- medical applications. ${ }^{13-24}$ Periodate oxidation of dextran is known to give polymeric dialdehydes with the elimination of formates. ${ }^{25-27}$ However, products from further oxidation with hypohalites, ${ }^{28}$ possibly polymeric dicarboxylates, have not been characterized yet. For applications to corrosion inhibitors, polycarboxylates with relatively low molecular weights are preferable because high molecular mass polymers would remain a long period in water phase before adsorbing onto the metal surface due to their low diffusivity. ${ }^{1}$ We chose dextran as a starting material because structure-defined oligomers are available, while various low molecular-weight biomass residues would in principle be applicable. Applying the Besemer's reaction conditions, ${ }^{12}$ we aimed at obtaining a highly carboxyl-substituted polymer by controlled and uncatalyzed oxidation of dextran with sodium hypochlorite $(\mathrm{NaClO}){ }^{29,30}$ Regioselective oxidation of dextran at the $\mathrm{C}_{2}$ and $\mathrm{C}_{4}$ atoms, allowing the control of molecular mass, was successfully accomplished, providing a polyether segment containing two carboxyl groups per repeating unit in the main chain. The choice of the oxidant, $\mathrm{NaClO}$, is also based on the anticipation that eutrophication of the cooling water containing the oxidized polysaccharide, which is intrinsically biodegradable and therefore nutritive, would be depressed by the sterilizing effect of the hypochlorite ion during the use of cooling water. The effect of corrosion inhibition was preliminarily investigated by corrosion weight loss tests.

${ }^{\dagger}$ To whom correspondence should be addressed (Tel: +81-4-7124-1501, Fax: +81-4-7121-2432, E-mail: yuasa@ @rs.noda.tus.ac.jp). 


\section{EXPERIMENTAL}

\section{Materials and Measurements}

Dextran (ICN Biomedicals Inc., $\mathrm{M}_{\mathrm{W}}=1.5-2 \times$ $10^{4}$ ), aqueous $\mathrm{NaClO}$ (Wako Chem., available chlorine $\geq 5 \%$ ), sodium hydroxide, and D-glucuronic acid were used as received. Poly(acrylic acid) (PAA) with a molecular weight of $M_{\mathrm{n}}=4500$ and a copolymer of acrylic acid and 2-acrylamido-2-methyl-1-propanesulfonic acid (co-PAA) with a molar composition of 75/ 25 and a molecular weight of $M_{\mathrm{n}}=4500$ were prepared as previously reported. ${ }^{1}$ GPC measurements were performed using Shimadzu LC-10AT equipped with a UV detector (Shimadzu SPD-10A) and Shodex Protein KW-804. Fluorescein isothiocyanate-dextran from Sigma-Aldrich $\left(\mathrm{M}_{\mathrm{W}}=2.82 \times 10^{5}\right.$ and $4.64 \times$ $\left.10^{5}\right)$, catalase $\left(1.0 \times 10^{5}\right)$, albumin $\left(8.0 \times 10^{4}\right)$, myoglobin $\left(1.65 \times 10^{4}\right)$, and cytochrome $c\left(1.2 \times 10^{4}\right)$ were used as molecular-weight standards. The eluent was a $0.1 \mathrm{M}$ phosphate buffer prepared from $\mathrm{KH}_{2} \mathrm{PO}_{4}$ $(>99.5 \%)$ and $\mathrm{K}_{2} \mathrm{HPO}_{4}(>99.5 \%)$ which were obtained from Wako Chem. and used as received. The detection wavelength was $280 \mathrm{~nm}$. NMR spectra were obtained using JEOL $300 \mathrm{MHz}$ JNM-AL300 spectrometer with 3-(trimethylsilyl)propionic-2,2,3,3- $d_{4}$ acid sodium salt (TMSP) from Sigma-Aldrich as an internal standard. IR spectra were obtained using JASCO FT/IR-410 spectrometer and a $\mathrm{KBr}$ pellet or a $\mathrm{CaF}_{2}$ cell with an optical path length of $20 \mu \mathrm{m}$. Lyophilization was carried out using a Kyowa Triomaster II A-04 freeze-drying system.

\section{Preparative Methods}

Oxidation of dextran was carried out with various amounts of $\mathrm{NaClO}$ at room temperature. In a typical procedure, to a $100 \mathrm{~mL}$ aqueous solution of dextran $(1.0 \mathrm{~g}, 6.2 \mathrm{mmol}$ unit) containing $\mathrm{NaOH}(0.1 \mathrm{~N})$ was added the aqueous $\mathrm{NaClO}(25.6 \mathrm{~mL}, 1.28 \mathrm{~g}, 17 \mathrm{mmol})$. The resulting solution was stirred for $24 \mathrm{~h}$ at room temperature. In order to force the reaction to proceed, the same amount of $\mathrm{NaClO}(17 \mathrm{mmol})$ was added again to the solution, which was then kept stirring for further $2 \mathrm{~d}$. The polymeric product with a molecular weight of more than 5000 was fractionated by ultrafiltration on a polyethersulfone membrane (Millipore) and purified by dialysis in $\mathrm{H}_{2} \mathrm{O}$ using seamless cellulose tubing (UC24-32-100) from Sanko Chem. Lyophilization of the aqueous solution afforded the product 1 as a white powder. Yield: $88 \mathrm{wt} \%$. IR ( $\mathrm{KBr}$, $\left.\mathrm{cm}^{-1}\right): 1614\left(v_{\mathrm{C}=0}\right), 1417,1308,1246,1147,1107$, 1078, 1041, 1020, 914, 887, 808, 642. ${ }^{1} \mathrm{H}$ NMR $\left(\mathrm{D}_{2} \mathrm{O}\right.$, TMSP, ppm): $\delta 4.93(\mathrm{~m}, 1 \mathrm{H}), 4.31-3.54(\mathrm{~m}, 4.04 \mathrm{H})$. ${ }^{13} \mathrm{C}$ NMR $\left(\mathrm{D}_{2} \mathrm{O}, \mathrm{TMSP}, \mathrm{ppm}\right): \delta 179,176,106,101$, $82.1,79.5,76.6,74.5,73.4,72.7,68.7$. GPC: $M_{\mathrm{n}}=$

\section{$1.7 \times 10^{4}, M_{\mathrm{w}}=1.9 \times 10^{4}\left(M_{\mathrm{w}} / M_{\mathrm{n}}=1.1\right)$.}

Products with lower degree of oxidation were prepared by the oxidation of the same amount of dextran $(1.0 \mathrm{~g}, 6.2 \mathrm{mmol}$ unit) with less amounts of $\mathrm{NaClO}$ (17 mmol (2) or $9.4 \mathrm{mmol}(3))$ added at a time and reacted for $24 \mathrm{~h}$ under the same conditions. Analytical data for 2: Yield: $29 \mathrm{wt} \%$. ${ }^{1} \mathrm{H}$ NMR $\left(\mathrm{D}_{2} \mathrm{O}\right.$, TMSP, ppm): $\delta 4.96(\mathrm{~m}, 1 \mathrm{H}), 4.63-3.51(\mathrm{~m}, 4.44 \mathrm{H})$. GPC: $M_{\mathrm{n}}=1.8 \times 10^{4}, \quad M_{\mathrm{w}}=2.0 \times 10^{4} \quad\left(M_{\mathrm{w}} / M_{\mathrm{n}}=1.1\right)$. Analytical data for 3: Yield: $20 \mathrm{wt} \% .{ }^{1} \mathrm{H}$ NMR $\left(\mathrm{D}_{2} \mathrm{O}\right.$, TMSP, ppm): $\delta 4.97(\mathrm{~m}, 1 \mathrm{H}), 4.64-3.51(\mathrm{~m}, 4.88 \mathrm{H})$. GPC: $M_{\mathrm{n}}=1.9 \times 10^{4}, M_{\mathrm{w}}=2.1 \times 10^{4}\left(M_{\mathrm{w}} / M_{\mathrm{n}}=\right.$ 1.1).

\section{Characterization of the Product}

A working curve was prepared using absorbance at $1730 \mathrm{~cm}^{-1}\left(v_{\mathrm{C}=\mathrm{O}}\right)$ in the IR spectra for aqueous mixtures of dextran $\left(\left(\mathrm{C}_{6} \mathrm{H}_{10} \mathrm{O}_{5}\right)_{n}\right)$ and D-glucuronic acid $\left(\mathrm{C}_{6} \mathrm{H}_{10} \mathrm{O}_{7}\right)$ with various molar fractions. The amount of carboxyl groups in the product was roughly estimated by the absorbance at $1595 \mathrm{~cm}^{-1}\left(v_{\mathrm{C}=\mathrm{O}}\right)$, assuming that absorbances for carboxylic acid and carboxylate were identical.

The effect of corrosion inhibition was preliminarily investigated by corrosion weight loss tests of carbon steel using tap water at $35^{\circ} \mathrm{C}$ for $7 \mathrm{~d}$ with constant stirring in an open vessel. Analytical data for the tap water: $\mathrm{pH} 7.4$, electric conductivity $\left(\sigma_{\mathrm{RT}}\right)=172 \mu \mathrm{S} /$ $\mathrm{cm}$, and hardness $=58 \mathrm{mgCaCO}_{3} / \mathrm{L}$. The metal sample employed was a pretreated plate of mild steel JIS SS 400 with a dimension of $30 \times 50 \times 1 \mathrm{~mm},{ }^{4}$ which was polished with emery papers and washed thoroughly with $\mathrm{H}_{2} \mathrm{O}, \mathrm{CH}_{3} \mathrm{OH}$, and acetone under ultrasonic irradiation. Then, the metal plates were immersed into solution $(1 \mathrm{~L})$ containing various inhibitors. The corrosion rate, $v$, was defined as the rate of decrease in the weight of metal plates during exposure to corrosive atmosphere. The corrosion rate was obtained from $v=w \cdot A^{-1} t^{-1}$ where $w$ was the loss of weight in $\mathrm{mg}, A$ was the surface area of the sample in $\mathrm{dm}^{2}$, and $t$ was the period of exposure to the atmosphere in day, and thus expressed by a unit of $\mathrm{mg} \cdot \mathrm{dm}^{-2}$ day $^{-1}$ which was abbreviated as mdd. ${ }^{2}$ The corrosion rate of the steel in the absence of inhibitors (i.e. blank test) was normalized by averaging the results of several independent experiments, which were in the range of $(1.3 \pm 0.2) \times 10^{2}$ mdd as shown in Table I.

\section{RESULTS AND DISCUSSION}

The products 1-3 from the oxidation of dextran with $\mathrm{NaClO}$ was obtained as white powder without significant deliquescent properties. IR spectroscopy was used to investigate the changes in the structure 
Table I. Corrosion rates of steel in tap water at $35^{\circ} \mathrm{C}$ containing various inhibitors

\begin{tabular}{cccc}
\hline Inhibitor & $\begin{array}{c}\text { Degree of } \\
\text { oxidation }^{1)}\end{array}$ & $\begin{array}{c}\text { Concentration } \\
(\mathrm{mg} / \mathrm{L})\end{array}$ & $\begin{array}{c}\text { Corrosion rate } \\
\times 10^{-2}(\mathrm{mdd})\end{array}$ \\
\hline none $^{2)}$ & - & - & $1.3 \pm 0.2$ \\
\hline $\mathbf{1}$ & 0.65 & 100 & 0.014 \\
\hline \multirow{2}{*}{$\mathbf{2}$} & \multirow{2}{*}{0.34} & 10 & 1.2 \\
& & 50 & 0.59 \\
\multirow{2}{*}{$\mathbf{3}$} & \multirow{2}{*}{0.28} & 100 & 0.36 \\
\hline \multirow{2}{*}{ PAA } & - & 10 & 1.5 \\
& & 50 & 1.4 \\
\hline \multirow{2}{*}{ co-PAA } & - & 50 & 0.27 \\
& & 100 & 0.017 \\
\hline
\end{tabular}

${ }^{1)}$ Defined as $1-m / n$ for the structure in Scheme 1 determined from ${ }^{1} \mathrm{H}$ NMR measurements. ${ }^{2}$ Blank test. See Experimental Section for details.

of dextran following oxidation with $\mathrm{NaClO}$. Figure 1 compares the IR spectra of the oxidized product $\mathbf{1}$, D-glucuronic acid as the model compound of a saccharide bearing a carboxyl group, and dextran. A distinct absorption band at $1595 \mathrm{~cm}^{-1}$ in the oxidized dextran (Figure 1a) is indicative of the presence of carboxyl groups. The $\mathrm{C}=\mathrm{O}$ stretching frequency, red-shifted from that of D-glucuronic acid (Figure 1b), suggested that the carboxyl groups in the product formed a sodium salt. The formation of the caboxylate by the oxidation of dextran with $\mathrm{NaClO}$ is in contrast with the result obtained using a periodate in stead of $\mathrm{NaClO}$. Previous experiments using sodium periodate as an oxidant demonstrated the formation of an aldehyde, with an IR band at $1730 \mathrm{~cm}^{-1}$, typically observed for the $\mathrm{C}=\mathrm{O}$ stretching frequency of aldehydes. ${ }^{13}$ The absence of aldehyde groups in $\mathbf{1}$ was also confirmed by NMR spectroscopy (vide infra).

In analogy to the dextran dialdehyde given by the periodate oxidation, it seems reasonable to suppose that oxidation of dextran with $\mathrm{NaClO}$ provides a dextran dicarboxylate having the carboxyl groups at $\mathrm{C}_{2}$ and $\mathrm{C}_{4}$ positions of the pristine dextran (Scheme 1). The very small absorbance near $1595 \mathrm{~cm}^{-1}$ for pristine dextran (Figure 1c) allowed determination of

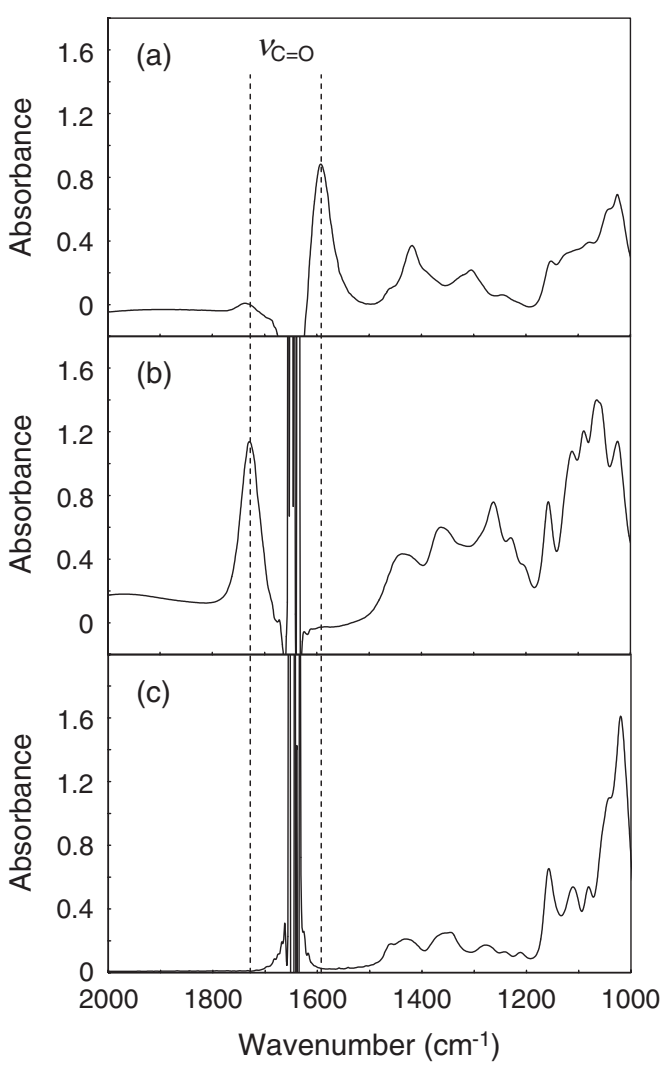

Figure 1. IR spectra for solutions prepared by dissolving (a) the oxidized dextran (1) $(59.4 \mathrm{mg})$, (b) D-glucuronic acid (103 mg, $1.76 \mathrm{~mol} / \mathrm{L})$, and (c) dextran $(50.2 \mathrm{mg}, 1.03 \mathrm{~mol} / \mathrm{L})$ in $\mathrm{H}_{2} \mathrm{O}(300 \mu \mathrm{L}) . \mathrm{A} \mathrm{CaF}_{2}$ cell with an optical path length of $20 \mu \mathrm{m}$ was used.

the carboxyl groups in the product. The absorbance for the $\mathrm{C}=\mathrm{O}$ stretching band of D-glucuronic acid $\left(3.2 \times 10^{2} \mathrm{Abs} \cdot \mathrm{cm}^{-1} \mathrm{M}^{-1}\right)$ provided a measure of the amount of carboxyl groups. The $\mathrm{C}=\mathrm{O}$ absorbance for the oxidized dextran 1 corresponded to $c a$. 1.5 carboxyl groups per repeating unit, which was roughly in agreement with the more precise value (i.e. 1.3 per repeating unit) calculated from a ${ }^{1} \mathrm{H}$ NMR spectrum (vide infra).

${ }^{13} \mathrm{C}$ NMR spectroscopy was attempted to further confirm the structural changes accompanied by the oxidation of dextran. Figure 2 shows the ${ }^{13} \mathrm{C}$ NMR spectra for dextran before and after the oxidation with $\mathrm{NaClO}$. For pristine dextran (Figure 2b), the peak at
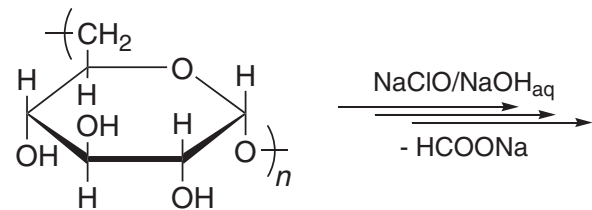

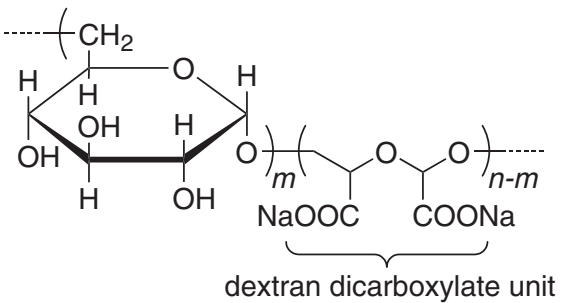

Scheme 1. 


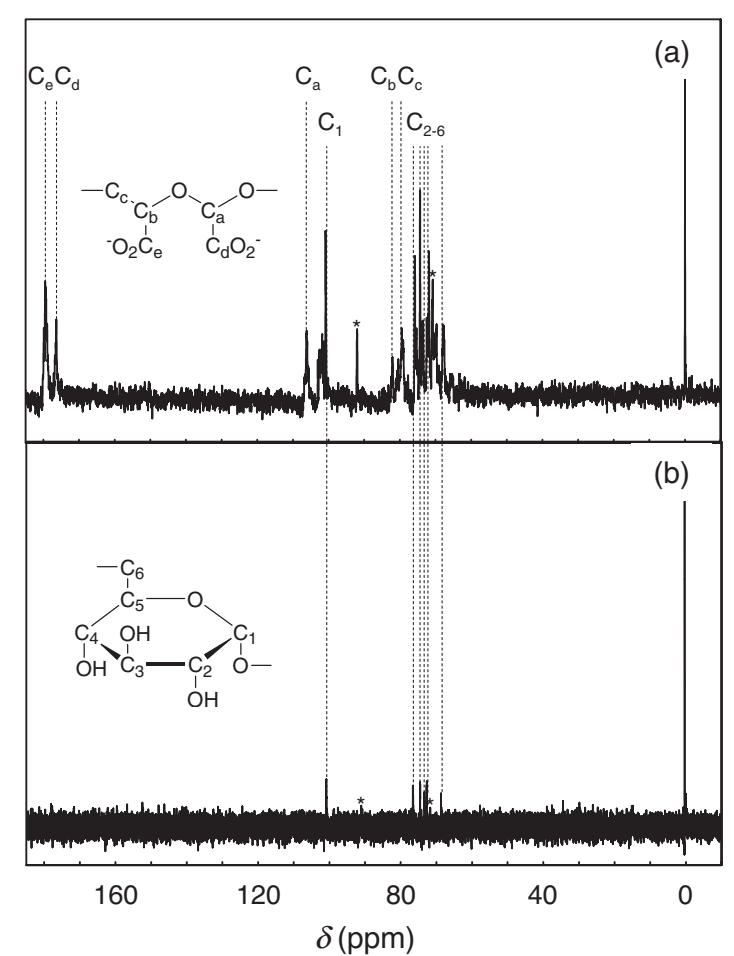

Figure 2. ${ }^{13} \mathrm{C}$ NMR spectra for (a) the oxidized dextran (1) and (b) dextran in $\mathrm{D}_{2} \mathrm{O}$ using TMSP as an internal standard. Resonances due to impurities in pristine dextran are shown as asterisks.

$101 \mathrm{ppm}$ represents the resonance for the $\mathrm{C}_{1}$ carbon of the glycoside linkage, while the other five peaks near $70 \mathrm{ppm}$ are made up of those for cyclic carbons of the glucose unit. It is apparent that oxidation leads to significant changes in the spectrum of dextran. In Figure $2 \mathrm{a}$, the carboxyl carbon resonances that would be expected near $180 \mathrm{ppm}$ appeared as two peaks at 179 and $176 \mathrm{ppm}$. The peaks for the $\mathrm{C}_{1}$ atom at $101 \mathrm{ppm}$ and the $\mathrm{C}_{5}$ atom at $72.7 \mathrm{ppm}$ in dextran shifted downfield to those at 106 and $82.0 \mathrm{ppm}$ for $\mathrm{C}_{\mathrm{a}}$ and $\mathrm{C}_{\mathrm{b}}$ atoms, respectively, as a result of the proximity of these carbons to the oxidation site. The other peak at $79.5 \mathrm{ppm}$ is most likely ascribed to the $\mathrm{C}_{\mathrm{c}}$ carbon. These spectroscopic results revealed that the product, after the oxidation with $\mathrm{NaClO}$, contained a polyether segment bearing two carboxyl groups per repeating unit, in addition to the glucose unit as shown in Scheme 1.

A noteworthy aspect for the oxidation of dextran with $\mathrm{NaClO}$ is the high selectivity to give the dextran dicarboxylate segment. Carbon resonances due to aldehydes that typically appear near $200 \mathrm{ppm}$ were not found. The spectrum for the oxidized dextran was made up only of resonances ascribed to the carbons in pristine dextran and those of the dicarboxylate unit. These results suggested that the oxidation took place only at the $\mathrm{C}_{2}$ and $\mathrm{C}_{4}$ positions according to

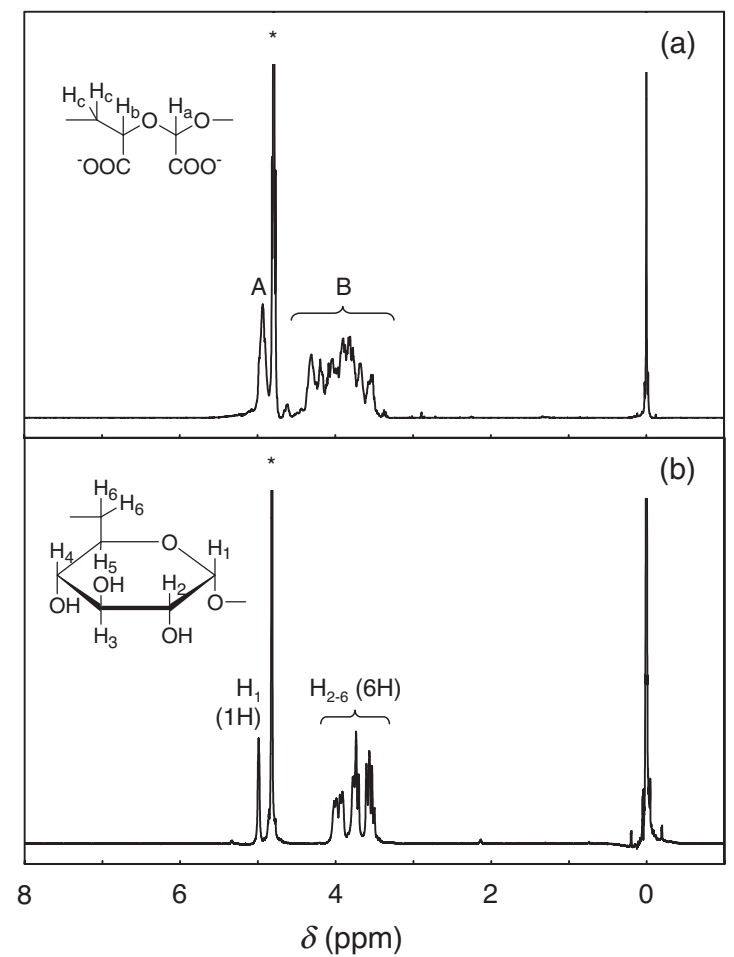

Figure 3. ${ }^{1} \mathrm{H}$ NMR spectra for (a) the oxidized dextran (1) and (b) dextran in $\mathrm{D}_{2} \mathrm{O}$ using TMSP as an internal standard. Resonances from residual $\mathrm{H}_{2} \mathrm{O}$ in $\mathrm{D}_{2} \mathrm{O}$ are shown as asterisks.

Scheme 1, consistent with the lack of molecular weight degradation as evidenced by the GPC analysis (see Experimental Section).

${ }^{1} \mathrm{H}$ NMR spectra for $\mathbf{1}$ and dextran are shown in Figure 3. In the spectrum of dextran, a singlet peak at $4.99 \mathrm{ppm}$ was ascribed to the $\mathrm{H}_{1}$ proton (Figure $3 \mathrm{~b}$ ). The other aliphatic protons showed unresolved peaks near $4 \mathrm{ppm}$, while integration of these peaks revealed that 6 protons were involved, consistent with the structure of dextran. In Figure 3a, a single peak labeled A centered at $4.93 \mathrm{ppm}$ is ascribed to the unresolved resonances from the $\mathrm{H}_{1}$ proton in the glucose unit and the $\mathrm{H}_{\mathrm{a}}$ proton in the dicarboxylate unit. A group of unresolved peaks labeled B near $4 \mathrm{ppm}$ is ascribed to the resonance from the aliphatic protons (i.e. $\mathrm{H}_{\mathrm{b}}, \mathrm{H}_{\mathrm{c}}$, and $\mathrm{H}_{2-6}$ ). Having established the primary structure of the oxidized dextran by ${ }^{13} \mathrm{C}$ NMR, the molar composition of the glucose unit and the dicarboxylate unit is determined from $m / n=I_{\mathrm{B}} /\left(3 I_{\mathrm{A}}\right)-$ 1 , where $I_{\mathrm{A}}$ and $I_{\mathrm{B}}$ are the integration of the peak area in the regions $\mathrm{A}$ and $\mathrm{B}$, respectively. A relative area of $I_{\mathrm{B}} / I_{\mathrm{A}}=4.04$ in Figure $3 \mathrm{a}$ afforded the degree of oxidation of $1-m / n=0.65$ for 1 , which corresponded to the amount of 1.3 carboxyl groups per repeating unit and was comparable to the value obtained from IR measurements.

Attempts to further increase the amount of the oxidized segment by oxidation with a larger amount of 
$\mathrm{NaClO}$ was unsuccessful, providing a lower molecular-weight products. Reasoning that selectivity of the reaction might be lowered at higher concentrations of $\mathrm{NaClO}$, we turned to the control of the degree of oxidation by varying the amount of the oxidant less than which was used for $\mathbf{1}$. The composition of the oxidized dextran, including those with lower degree of oxidation, is summarized in Table I, together with the results of corrosion weight loss tests. The corrosion rate significantly decreased with increasing the concentration of the oxidized dextran, and with increasing the degree of oxidation. The corrosion rate in the presence of $100 \mathrm{mg} / \mathrm{L}$ of $\mathbf{1}$ was almost comparable to that observed for $100 \mathrm{mg} / \mathrm{L}$ of PAA. The lack of inhibition effect for pristine dextran, and the structure of $\mathbf{1}$ closely related to that of PAA, suggest that the oxidized dextran acts as an adsorption-type inhibitor, in which the carboxyl groups adsorb on steel to form a film, thereby depressing the corrosion of steel.

The adsorption of $\mathbf{1}$ onto steel was suggested by a significant decrease in the concentration of $\mathbf{1}$ upon addition of iron powder to the aqueous solution of $\mathbf{1}$. Comparison of the absorbance at $282 \mathrm{~nm}$ due to the $\mathrm{n} \rightarrow \pi^{*}$ transition of the carbonyl groups in the UV spectra of 1 revealed that $c a .27 \%$ of $\mathbf{1}$ adsorbed on iron by adding $0.6 \mathrm{~g}$ of iron powder ( $325 \mathrm{mesh}$, total surface area $\approx 1 \times 10^{2} \mathrm{~cm}^{2}$ ) to the $10 \mathrm{~mL}$ aqueous solution of $1(0.07 \mathrm{~g})$. The amount of adsorption is comparable to those reported for poly(acrylate) derivatives in our previous studies. ${ }^{1}$

Both limited formation of scale during the corrosion test and biodegradability, based on preliminary bacterial culture experiments, were observed for the oxidized dextran 1-3. The precise evaluation of the inhibition effect, determined per amount of the carboxyl group, and electroanalysis of the inhibition mechanism, are the topics of our continuous research.

\section{CONCLUSIONS}

Controlled evolution of polyether segment having carboxyl groups in dextran was accomplished by the oxidation of dextran with $\mathrm{NaClO} .{ }^{1} \mathrm{H}$ NMR spectroscopy provided a simple method to determine the amount of the carboxyl groups. The product showed moderate inhibition efficiency for the corrosion of mild steel, comparable to that of PAA. The utilization of abundant biomass residues as sources for corrosion inhibitors will be a new approach to improve the ecological and economical balance of corrosion inhibition techniques.

Acknowledgment. This research was partially supported by a Grant-in-Aid for Scientific Research (Nos. 16550128 and 17550138) from MEXT, Japan.

\section{REFERENCES}

1. I. Sekine, M. Sanbongi, H. Hagiuda, T. Oshibe, M. Yuasa, T. Imahama, Y. Shibata, and T. Wake, J. Electrochem. Soc., 139, 3167 (1992).

2. M. Yuasa, T. Oshibe, T. Ishii, A. Suzuki, T. Aizawa, H. Yajima, K. Akiyama, I. Sekine, T. Imahama, T. Wake, H. Murata, and Y. Shibata, J. Surface Finish. Soc. Jpn., 50, 1147 (1999).

3. I. Sekine, T. Shimode, M. Yuasa, and K. Takaoka, Ind. Eng. Chem. Res., 31, 434 (1992).

4. I. Sekine, T. Shimode, M. Yuasa, and T. Takaoka, Ind. Eng. Chem. Res., 29, 1460 (1990).

5. I. Sekine, Y. Nakahata, and T. Tanabe, Corros. Sci., 28, 987 (1988).

6. I. Sekine and Y. Hirakawa, Corrosion, 42, 272 (1986).

7. K. Maurer and G. Drefahl, Ber., 75, 1489 (1942).

8. E. C. Yackel and W. O. Kenyon, J. Am. Chem. Soc., 64, 121 (1942).

9. T. J. Painter, Carbohydr. Res., 55, 95 (1977).

10. H. van Bekkum, in "Carbohydrates as Organic Raw Materials,” F. W. Lichtenthaler, Ed., VCH, Weinheim, 1991, p 289.

11. G. O. Aspinall and A. Nicolson, J. Chem. Soc., 2503 (1960).

12. A. E. J. de Nooy, A. C. Besemer, and H. van Bekkum, Carbohydr. Res., 269, 89 (1995).

13. R. Y. Cheung, Y. Ying, A. M. Rauth, N. Marcon, and X. Y. Wu, Biomaterials, 26, 5375 (2005).

14. R. Rebizak, M. Schaefer, and É. Dellacherie, Bioconjugate Chem., 8, 605 (1997).

15. R. Gref, J. Rodrigues, and P. Couvreur, Macromolecules, 35, 9861 (2002).

16. F. E. Armitage, D. E. Richardson, and K. C. P. Li, Bioconjugate Chem., 1, 365 (1990).

17. S. C. Wang, M. G. Wikstroem, D. L. White, J. Klaveness, E. Holtz, P. Rongved, M. E. Moseley, E. Michael, and R. C. Brash, Radiology, 175, 483 (1990).

18. S. W. A. Bligh, C. T. Harding, P. J. Sadler, R. A. Bulman, G. M. Bydder, J. M. Pennoock, J. D. Kelly, I. A. Latham, and J. A. Marriott, Magn. Reson. Med., 17, 516 (1991).

19. P. Rongved and J. Claveness, Carbohydr. Res., 214, 315 (1991).

20. É. Dellacherie, in "Polysaccharides in Medicinal Applications," S. Dumitriu, Ed., Marcel Dekker, New York, 1996, p 525.

21. V. A. Izumrudov, F. Chaubet, A.-S. Clairbois, and J. Jozefonvicz, Macromol. Chem. Phys., 200, 1753 (1999).

22. M. Nichifor, M. C. Stanciu, and X. X. Zhu, React. Funct. Polym., 59, 141 (2004).

23. Y. Jia, F. Wood, P. Menu, B. Faivre, A. Caron, and A. I. Alayash, Biochim. Biophys. Acta, 1672, 164 (2004).

24. M. Maire, D. Logeart-Avramoglou, M.-C. Degat, and F. Chaubet, Biomaterials, 26, 1771 (2005).

25. J. W. Sloan, B. H. Alexander, R. L. Lohmar, I. A. Wolff, and C. E. Rist, J. Am. Chem. Soc., 76, 4429 (1954).

26. J. C. Rankin and A. Jeanes, J. Am. Chem. Soc., 76, 4435 (1954).

27. A. Jeanes and C. A. Wilham, J. Am. Chem. Soc., 72, 2655 (1950). 
28. H. F. Launer and Y. Tomimatsu, Anal. Chem., 26, 382 (1954).

29. Z. R. Bright, C. R. Luyeye, A. S. M. Morton, M. Sedenko, R. G. Landolt, M. J. Bronzi, K. M. Bohovic, M. W. A.
Gonser, T. E. Lapainis, and W. H. Hendrickson, J. Org. Chem., 70, 684 (2005).

30. M. P. VanBrunt, R. O. Ambenge, and S. M. Weinreb, J. Org. Chem., 68, 3323 (2003). 